\title{
Ecringto
}

Revista Legado de Arquitectura y Diseño

ISSN: 2007-3615

ISSN: 2448-749X

legado_fad@yahoo.com.mx

Universidad Autónoma del Estado de México

México

\section{TÉLESIS Y DISEÑO: ANÁLISIS DEL PAPEL DE LAS CONDICIONANTES CULTURALES EN LOS CAMBIOS PARADIGMÁTICOS}

Solano-Meneses, Eska Elena

TÉLESIS Y DISEÑO: ANÁLISIS DEL PAPEL DE LAS CONDICIONANTES CULTURALES EN LOS CAMBIOS PARADIGMÁTICOS

Revista Legado de Arquitectura y Diseño, vol. 2019, núm. 26, 2019

Universidad Autónoma del Estado de México, México

Disponible en: http://www.redalyc.org/articulo.oa?id=477961406013

Esta obra está bajo una Licencia Creative Commons Atribución-NoComercial-SinDerivar 4.0 Internacional. 


\title{
TÉLESIS Y DISEÑO: ANÁLISIS DEL PAPEL DE LAS CONDICIONANTES CULTURALES EN LOS CAMBIOS PARADIGMÁTICOS
}

\author{
TELESIS AND DESIGN: ANALYSIS OF THE ROLE \\ OF CULTURAL CONDITIONS IN PARADIGMATIC \\ CHANGES
}

\author{
Eska Elena Solano-Meneses eskasolano@gmail.com \\ Universidad Autónoma del Estado de México, México
} Revista Legado de Arquitectura y Diseño,
vol. 2019, núm. 26, 2019

Universidad Autónoma del Estado de México, México

Recepción: 23 Marzo 2019 Aprobación: 03 Junio 2019

Redalyc: http://www.redalyc.org/ articulo.oa?id=477961406013
Resumen: Este trabajo analiza la relación del diseño con las condicionantes culturales, pasadas y presentes, valorando la télesis como posible cualidad del diseño, a través de una metodología basada en categorías propuestas por la autora, que determinan la tendencia del diseño en sus etapas históricas. Estas tres categorías son: a) Aspectos funcionales. b) Aspectos formales/estético y c) Aspectos simbólicos; donde lo simbólico establece el nexo más fuerte con lo cultural. La base para sustentar una visión completa es una revisión retrospectiva, para ello se desarrolla una revisión sintética de las diferentes etapas o paradigmas del diseño.

El análisis es desarrollado a un nivel inferencial, dado que parte de buscar relaciones categóricas, establece comparaciones entre los distintos paradigmas de diseño y al final permite la construcción de un modelo que pretende sintetizar la tendencia hacia una iteración cíclica, con la que aparentemente se ha comportado el diseño.

Se concluye que racionalizar el enfoque contextual en los diseñadores contribuirá para que la propuesta de diseño sea consciente, situada y sistematizada. Una propuesta de la que se desprende la importancia de que el diseñador comprenda de una manera holística las condicionantes en las que está inmerso el usuario, para así responder a sus necesidades reales y satisfacerle en las tres categorías mencionadas.

Palabras clave: condicionante cultural, diseño, télesis.

Abstract: This paper analyzes the relationship of design with cultural conditions, past and present, valuing telesis as a possible quality of design, through a methodology based on categories proposed by the author, which determine the trend of design in its historical stages. These three categories are: a) Functional Aspects. b) Formal/Aesthetic aspects and c) Symbolic aspects; where the symbolic establishes the strongest link with the cultural. The basis for supporting a complete vision is a retrospective review, and for this a synthetic review of the different stages or paradigms of the design is developed.

The analysis is developed at an inferential level, since part of looking for categorical relationships, establishes comparisons between the different design paradigms and in the end, allows the construction of a model that aims to synthesize the trend towards a cyclic iteration, with which apparently the design has behaved.

It is concluded that streamlining the contextual approach in designers will contribute so that the design proposal is conscious, located and systematized. A proposal that shows the importance of the designer to understand in a holistic way the conditions in which the user is immersed, in order to respond to his real needs and satisfy him in the three categories mentioned.

Keywords: cultural conditioning, telesis, design. 


\section{INTRODUCCIÓN}

El presente trabajo se centra en el análisis de las causas que han propiciado los cambios en los paradigmas del diseño, discriminando la naturaleza de esta evolución, ya sea, producto de especulaciones y situaciones creadas artificialmente, o producto de las condicionantes culturales que, telésicamente, van definiendo sus cambios congruentemente con las necesidades y deseos de una época.

De este modo, el objetivo principal es analizar la relación que existe entre el diseño y las condicionantes culturales que le conforman, a través de una revisión longitudinal (histórica y en prospectiva), así como transversal (bajo una revisión contextual) para analizar si los cambios en cada etapa cumplen con las condiciones telésicas ya antes descritas, según las cuales responden a las condicionante culturales o mantienen un carácter desprovisto de relación con el contexto.

\section{La discusión pone sobre la mesa \\ EL CONCEPTO TÉLESIS, QUE SIRVE DE REFERENCIA PARA EVALUAR EL DISENO en relación con las condicionantes culturales.}

La discusión pone sobre la mesa el concepto télesis, que sirve de referencia para evaluar el diseño en relación con las condicionantes culturales. Con este concepto de télesis, el cuestionamiento se centra en la relación que guardan los procesos evolutivos del diseño a lo largo de la historia con los contextos culturales, que se pueden configurar como condicionantes.

Este análisis responde a la pregunta de investigación: en qué medida, el diseño y su evolución obedece a cuestiones serendípicas (como descubrimientos azarosos de materiales o metodologías en otros campos); posturas caprichosas sin vínculos contextuales o a condicionantes culturales más antrópicas como formas de vida y pensamiento.

El método empleado para este análisis obedece a dos sentidos: el histórico (longitudinal) y el relativo (transversal), lo que conlleva a la consideración de las condicionantes culturales como contraposición, que se evalúan bajo tres categorías propuestas: a) Aspectos funcionales. b). Aspectos formales/estético y c). Aspectos simbólicos, donde es considerado el aspecto simbólico como el que muestra la carga cultural más evidente.

Los resultados del análisis realizado son que a lo largo de las diferentes etapas históricas existe un comportamiento iterativo del diseño que deambula entre las tres categorías identificadas: lo funcional, lo formal/estético y lo simbólico, aunque, asimismo, algunas etapas se han caracterizado por estar dominadas por dicotomías. Los resultados evidencian una dinámica cíclica, donde los discursos del diseño oscilan entre la mesura y el recargo, entre lo estrictamente funcional y lo formal/ estético, para en ciertos momentos incursionar en lo simbólico. Como se aprecia, a lo largo de la historia el diseño ha oscilado entre las tres 
categorías mencionadas, siendo iterativa la carga que las condicionantes culturales han tenido.

Se concluye que el diseño se ha mostrado a lo largo de algunas etapas de su historia de una manera telésica que ha ido respondiendo a las múltiples necesidades humanas y a sus condicionantes culturales, que evidentemente van de la mano. Pero también ha evidenciado que las hegemonías de algunos planteamientos teóricos pueden detonar en planteamientos que alejan el discurso de una realidad.

La aportación de este trabajo es la reflexión de la necesidad de generar un compromiso en los diseñadores, para que privilegien un diseño congruente a su momento cultural y no impongan discursos que alejen al diseño de la naturaleza humana en aras de un capricho o interés económico.

\section{ANTECEDENTES}

La evolución es el agente regulador del sistema, según García, "los sistemas sufren transformaciones en su desarrollo temporal. Esta evolución procede por una serie de desequilibrios y reequilibraciones que conducen a sucesivas reorganizaciones" (2011: 199). Estas relaciones evolutivas de desorganización y reorganización conducen a una percepción compleja del diseño, en la que: “....no hay objeto si no es con respecto al sujeto y no hay sujeto si no es con respecto a un ambiente objetivo" (Morin, 2009: 97).

En esta postura queda evidente la relación dialógica objeto-sujeto que con Morín permite mantener la dualidad entre el diseño (objeto) y las condicionantes culturales (sujeto).

El diseñador ha comprendido que su labor más que definitoria es estratégica: ha de ir determinando sus propuestas bajo un enfoque sistémico, donde se atiendan todas las necesidades implícitas en el objeto de diseño, que van desde lo funcional, formal, emocional y simbólico. $\mathrm{Su}$ acercamiento a ciencias y métodos culturales como la antropología, la sociología y la etnografía han permitido comprender, que los principios que rigen el diseño no le son endógenos, sino que devienen de la sociedad misma. Como afirma Solano (2012: 35), la naturaleza de las cosas ha demostrado, que en el universo nada se rige por leyes rigurosas, y que tanto los fenómenos naturales como culturales se encuentran inmersos en una serie de factores que los determinan, y que se encuentran interconectados, en constante fluctuaciones y reorganizaciones.

Su acercamiento a ciencias y métodos culturales como LA ANTROPOLOGÍA, LA SOCIOLOGÍA Y LA ETNOGRAFÍA HAN PERMITIDO COMPRENDER, QUE LOS PRINCIPIOS QUE RIGEN EL DISEÑO NO LE SON ENDÓGENOS. sino que devienen de la sociedad misma.

El enfoque contextual y configurativo del diseño posibilita la pertinencia de su propuesta, y es imperativo promoverlo en los diseñadores. 
Independientemente de estar sujeto a variables como las tecnológicas, ergonómicas, funcionales, etc.; el diseñador debe estar ahora y en el futuro atento a las cuestiones culturales, que son las que permiten ofrecer desde el diseño, alternativas que satisfagan los requerimientos más profundos de su usuario.

\section{MARCO TEÓRICO: LA TÉLESIS Y LAS CONDICIONANTES CULTURALES EN EL DISEÑO}

La pertinencia entre el diseño y las condicionantes culturales de cada época es cuestionada. El distanciamiento con la télesis implica una postura del diseño sin referencia por su contexto, resultado de ideas ajenas a una necesidad real, y más cercana a caprichos, modas o conveniencias económicas.

Papanek establece una dura critica contra el diseño, que no es acorde a los cambios sociales y culturales, y propone el contexto cultural como uno de los puntos a considerar en el diseño, lo que denomina "el contenido telésico", según el cual "debe reflejar la época y las condiciones que le han dado lugar, y debe ajustarse al orden humano socio-económico general en el cual va a actuar" (Papanek, 2014: 38). La propuesta de este autor establece una visión funcional del diseño, misma que estará definida por seis aspectos a considerar: método, utilización, necesidad, estética, asociación y télesis.

El concepto de télesis, creado por Lester Frank Ward, se entiende como la dirección inteligente de un esfuerzo hacia el alcance de una meta específica, es decir, una adaptación estratégica. El concepto télesis ha servido para entender la evolución histórica del diseño como resultado de su relación fenomenológica con el contexto cultural, lo que da lugar a reorganizaciones constantes que se apoyan en la comprensión del contexto y que provocan los cambios paradigmáticos que se analizarán en este texto. A ello se debe que Papanek lo haya integrado como la base de un diseño más racional.

Margolín (2005: 314), por su parte, afirma que los productos de diseño revelan hechos importantes de la vida humana, y en esto sustenta su perspectiva de la historia del diseño, reconociendo la relación del diseño y su sustrato cultural.

La cultura es el amalgamiento de un pueblo, es lo que les identifica de otro grupo social (Solano, 2012: 69). Acorde a Mélich (1998: 58), "el ser humano encuentra sentido a su existencia a través de esquemas culturales, que son simbólicos", de este modo, se entienden por esquemas o modelos culturales al sistema de símbolos, cuyas relaciones entre sí, modelan las relaciones entre identidades y procesos. Para Mélich, los fenómenos culturales son, primeramente, simbólicos y significativos. "El símbolo es un signo que ofrece un significado manifiesto y un significado oculto, solo detectable y comprensible para quien está iniciado en él" (Beuchot, 2008: 140). Existe en el hombre una férrea necesidad de este sistema de símbolos culturales, los cuales son el soporte de la cosmovisión del hombre, entendida ésta como su manera de ver y entender la vida, le dan 
sentido y coherencia a su existencia. Siguiendo a Geertz, "la cultura denota un esquema históricamente transmitido de significaciones representadas en símbolos, por medio de los cuales los hombres comunican, perpetúan y desarrollan su conocimiento y sus actitudes frente a la vida” (2000: 88).

\section{Con ello se concede a LOS SIMMBOLOS Y A LA CULTURA UN PAPEL SUSTENTANTE del quehacer del hombre y su diseño.}

Con ello se concede a los símbolos y a la cultura un papel sustentante del quehacer del hombre y su diseño.

La relevancia actual del paradigma del diseño como una concreción de condicionantes humanas que parten de una cosmovisión responde claramente a un giro cultural, donde se refiere al diseño y a la cultura como procesos simbólicos de una sociedad.

Este giro cultural propugna por una reconsideración de los enfoques con los que se había mirado al hombre y sus manifestaciones (Jamenson, 1999:192) y centra su atención en aspectos culturales de gran importancia para el concepto de diseño.

Para Giménez (2001: 17), "la cultura tendría que concebirse como el conjunto de hechos simbólicos presentes en una sociedad o como la organización social del sentido como pautas de significados". Con el diseño, el hombre encuentra una manera de darle sentido a la vida, al proporcionarle medios para solucionar actividades diarias o acompañar ritos. Desde sus diferentes manifestaciones: gráficas, industriales, espaciales, etc.; el diseño manifiesta las condicionantes subyugantes de la época. Las condicionantes tecnológicas, ideológicas, económicas, etc.; se mezclan y se amalgaman en cualquiera de los productos de diseño.

A través del diseño el hombre encuentra sentido a su existencia y regula su mundo circundante, al tiempo que concede al diseño características que revelan y hacen reconocible sus formas de vida. Cada objeto de diseño es portador de significados, retrata su contexto, describe su uso e importancia, contribuye a la comprensión de su época, acusa paradigmas prevalecientes y con ello se convierte en el texto de análisis cultural más evidente para el investigador.

\section{METODOLOGÍA DE LA INVESTIGACIÓN: LOS PARADIGMAS DEL DISEÑO, UN ANÁLISIS LONGITUDINAL Y TRANSVERSAL}

El método propuesto implica el establecimiento de categorías que determinan la tendencia del diseño en todas sus etapas históricas, consideradas como cambios paradigmáticos, mismas que se distinguen entre funcionales, formales/estéticas y simbólicas, donde lo simbólico representa la carga generada por las condicionantes culturales. 
Con base a estas categorías se realiza un recorte histórico por etapas, considerando para su delimitación el cambio paradigmático entre las categorías imperantes en el diseño.

Posteriormente se contrastan los resultados con la intención de identificar el comportamiento de dichas categorías en su carácter definitorio de las tendencias del diseño a lo largo de la historia, para con ello comprender la razón casual o causal del diseño.

Con ello se hace hincapié en el compromiso formativo del diseñador de estar en constante diálogo con sus condicionantes culturales y bajo este enfoque diseñar sus proyectos.

\section{DESARROLLO: LOS CAMBIOS PARADIGMÁTICOS DEL DISEÑO COMO RESPUESTA A LAS CONDICIONANTES CULTURALES}

Como se describe en la metodología, la base para este análisis es una revisión sintética de las diferentes etapas del diseño, consideradas éstas bajo el criterio de verdaderos cambios paradigmáticos, es decir, periodos de marcados cambios respecto de la etapa anterior.

Con intención analítica se han considerado seis paradigmas en la historia del diseño (tabla 1), estas son:

- Diseño en la Prehistoria

- Diseño en la Etapa Antigua (siglo V a.C. al XIV d.C.)

- Diseño en la Etapa Moderna (siglo XV al XVIII)

- Diseño en el siglo XIX

- Diseño en el siglo XX (primeros 70 años)

- Diseño en la Posmodernidad (desde los años 70). 
Tabla 1. Esquema de los cambios paradigmáticos en el Diseño.

\begin{tabular}{|c|c|c|c|c|}
\hline Paradigma & $\begin{array}{l}\text { Aspectos } \\
\text { funcionales }\end{array}$ & \begin{tabular}{|l|} 
Aspectos \\
formales/estéticos
\end{tabular} & $\begin{array}{l}\text { Aspectos } \\
\text { simbólicos }\end{array}$ & $\begin{array}{l}\text { Tendencia del } \\
\text { Diseño }\end{array}$ \\
\hline $\begin{array}{l}\text { Diseño en la } \\
\text { prehistoria }\end{array}$ & $\begin{array}{l}\text { Satisfacción } \\
\text { pragmática de } \\
\text { las } \\
\text { necesidades } \\
\text { fundamentales, } \\
\text { Sin intención } \\
\text { estética y } \\
\text { concepto } \\
\text { primitivo de } \\
\text { confort. }\end{array}$ & $\begin{array}{l}\text { No atendidos. } \\
\text { Imitación de la } \\
\text { naturaleza como } \\
\text { analogía y } \\
\text { muestra de lo } \\
\text { perfecto e } \\
\text { imitable. }\end{array}$ & \begin{tabular}{|l|} 
Satisfacción \\
de objetos \\
simbólicos, \\
referencia a la \\
fecundidad o \\
ritos de \\
sobrevivencia.
\end{tabular} & Simbólico-Funcional \\
\hline $\begin{array}{l}\text { Diseño en la } \\
\text { Etapa Antigua } \\
\text { (siglo V a.C. al } \\
\text { XIV d.C.) }\end{array}$ & \begin{tabular}{|l} 
Se infiere la \\
existencia de \\
un objeto \\
cotidiano de \\
alto \\
pragmatismo y \\
perecedero, \\
hoy no \\
conservado.
\end{tabular} & $\begin{array}{l}\text { Se privilegian } \\
\text { sobre la función, } \\
\text { lo estético se liga } \\
\text { al estatus. El } \\
\text { material como } \\
\text { elemento estético } \\
\text { y signo de poder } \\
\text { (materiales } \\
\text { cotizados: cacao, } \\
\text { oro, jade, plata, } \\
\text { mármol). }\end{array}$ & $\begin{array}{l}\text { Objetos } \\
\text { simbólicos } \\
\text { ligados a la } \\
\text { religión o al } \\
\text { poder } \\
\text { terrestre } \\
\text { (reyes, } \\
\text { faraones, } \\
\text { sacerdotes). }\end{array}$ & Simbólico -estética \\
\hline $\begin{array}{l}\text { Diseño en la } \\
\text { Etapa Moderna } \\
\text { (Siglo XV al } \\
\text { XVIII) }\end{array}$ & $\begin{array}{l}\text { Existencia de } \\
\text { un objeto } \\
\text { cotidiano de } \\
\text { alto } \\
\text { pragmatismo y } \\
\text { perecedero, } \\
\text { destinado a } \\
\text { labores } \\
\text { comunes y a la } \\
\text { clase social } \\
\text { baja. Lo } \\
\text { tecnológico se } \\
\text { aplica } \\
\text { orientado al } \\
\text { confort. }\end{array}$ & $\begin{array}{l}\text { Se privilegian } \\
\text { sobre la función y } \\
\text { el confort, lo } \\
\text { estético se liga al } \\
\text { estatus. El ornato } \\
\text { como signo de } \\
\text { refinamiento } \\
\text { prevalece sobre la } \\
\text { idea del valor del } \\
\text { material. }\end{array}$ & $\begin{array}{l}\text { Objetos } \\
\text { Simbólicos } \\
\text { ligados a la } \\
\text { aristocracia, } \\
\text { nobleza y } \\
\text { clero. }\end{array}$ & Estético -simbólico \\
\hline $\begin{array}{l}\text { Diseño en el } \\
\text { siglo XIX }\end{array}$ & \begin{tabular}{|l} 
En la \\
producción \\
industrial la \\
función se \\
impone ante la \\
recién \\
desarrollada \\
producción en \\
serie, se \\
resuelve la \\
necesidad, \\
pero se diluye \\
la estética. El \\
producto \\
industrial se \\
aleja de la \\
artesanía y del \\
trabajo \\
manual.
\end{tabular} & $\begin{array}{l}\text { Lo ornamental se } \\
\text { asocia a lo } \\
\text { manual y } \\
\text { artesanal. Por un } \\
\text { lado se aplaude el } \\
\text { progreso, pero las } \\
\text { formas refieren a } \\
\text { una nostalgia } \\
\text { hacia el pasado. }\end{array}$ & $\begin{array}{l}\text { Lo simbólico } \\
\text { se relaciona } \\
\text { con los } \\
\text { historicismos, } \\
\text { se acude a las } \\
\text { formas } \\
\text { antiguas para } \\
\text { enfrentar la } \\
\text { crisis } \\
\text { derivada del } \\
\text { producto } \\
\text { industrial } \\
\text { considerado } \\
\text { frío e } \\
\text { inhumano. }\end{array}$ & Funcional-estético \\
\hline $\begin{array}{l}\text { Diseño en el } \\
\text { Siglo XX }\end{array}$ & $\begin{array}{l}\text { Se privilegia la } \\
\text { función sobre } \\
\text { otros } \\
\text { principios del } \\
\text { diseño: } \\
\text { desarrollo y } \\
\text { teorización de } \\
\text { ideas como } \\
\text { ergonomía, } \\
\text { antropometría, } \\
\text { etcétera. }\end{array}$ & $\begin{array}{l}\text { El ornato se } \\
\text { elimina y se } \\
\text { recurre a la } \\
\text { estilización de los } \\
\text { componentes } \\
\text { esenciales del } \\
\text { objeto de diseño. } \\
\text { Existen limitantes } \\
\text { tecnológicos para } \\
\text { lo ornamental. }\end{array}$ & $\begin{array}{l}\text { Lo simbólico } \\
\text { se liga al arte, } \\
\text { a una } \\
\text { muestra de la } \\
\text { creación } \\
\text { artística del } \\
\text { hombre. El } \\
\text { valor del } \\
\text { objeto por el } \\
\text { objeto mismo: } \\
\text { Su estética, su } \\
\text { vanguardia. } \\
\text { El diseñador } \\
\text { se considera } \\
\text { una artista. El } \\
\text { objeto único o } \\
\text { de edición } \\
\text { limitada se } \\
\text { cotiza. }\end{array}$ & Funcional \\
\hline $\begin{array}{l}\text { Diseño en la } \\
\text { Posmodernidad }\end{array}$ & $\begin{array}{l}\text { La función se } \\
\text { atiende bajo el } \\
\text { concepto de } \\
\text { multifunción, } \\
\text { flexibilidad y } \\
\text { libre uso } \\
\text { potencialidad } \\
\text { del objeto. La } \\
\text { economia } \\
\text { como eje } \\
\text { rector (menor } \\
\text { inversión, } \\
\text { mayor } \\
\text { ganancia). }\end{array}$ & $\begin{array}{l}\text { Lo estético como } \\
\text { concepto } \\
\text { nostálgico: Retro, } \\
\text { Vintage, etc. La } \\
\text { estética simula } \\
\text { materiales con } \\
\text { productos } \\
\text { sintéticos. }\end{array}$ & \begin{tabular}{|l|} 
Lo simbólico \\
se liga a la \\
tecnología, \\
pero al mismo \\
tiempo se ciñe \\
a discursos \\
como lo \\
antrópico \\
(emocional, \\
cultural y \\
psicológico), \\
lo \\
Sustentable, \\
lo incluyente \\
y lo \\
identitario \\
como \\
respuesta a la \\
globalización. \\
\end{tabular} & Simbólico \\
\hline
\end{tabular}

Fuente: Solano, (2017) 


\section{Diseño en la Prehistoria}

Se considera la prehistoria, todas aquellas manifestaciones humanas previas a la existencia de los referentes escritos. En esta etapa, el hombre primitivo inicia con la adaptación, manipulación y construcción de materiales y objetos diversos para fines prácticos como la supervivencia (cacería, agricultura, recolección y pesca), además de la religión.

En el diseño en la prehistórica existe una fuerte carga por aspectos simbólicos y de manera secundaria lo funcional. En contraste, las cuestiones estéticas no se consideran primarias.

En este periodo se aprecia una satisfacción pragmática de las necesidades fundamentales, sin intención formal/estética: lo importante es que el objeto de diseño facilite la tarea, pero con un concepto primitivo de confort.

En lo estético, sin considerarse prioritario, se tiende a la imitación de la naturaleza como analogía al ser el modelo de la perfección.

Finalmente, lo simbólico rige: el peso mayor convierte al objeto en fetiche. Como evidencia de la importancia de los conceptos culturales se hace referencia a la fecundidad, como manera de continuación de la especie, así como a diversos ritos de sobrevivencia.

\section{Diseño en la Etapa Antigua (siglo V a.C. alXIV d.C.)}

La etapa antigua implica el inicio de la historia. Culturas como la mesopotámica, la griega, la romana, y periodos como la edad media se distinguieron por la importancia que conceden a las creencias y al valor agregado que dan al objeto ornamentado. El diseño de este periodo se define por el deseo de crear orden, proporción y armonía. La individualidad no existe en la misma estructura social en la que vive. Aparece la necesidad del hombre de subordinarse a un poder superior, de esta necesidad se entiende el gran poder que ostentó la religión cristiana. En la idiosincrasia medieval siempre operó la idea de que el espíritu es prisionero del cuerpo.

Bajo este paradigma se confiere mayor importancia a los valores simbólicos y estéticos. Aunque no se tienen numerosas evidencias, se infiere la existencia de un objeto cotidiano de alto pragmatismo y perecedero, objetos utilizados de manera para la facilitación de las tareas y actividades diarias con cierto grado de mejoramiento técnico referente al periodo anterior. Lo estético y formal se privilegian sobre la función, ya que lo ornamental del objeto se liga al estatus. Al mismo tiempo se consolidan códigos que detentan poder. Estos códigos se basan además en el ornamento y el material: los objetos simbólicos se construyen con materiales caros y altamente cotizados, tal es el caso del: cacao, oro, jade, plata, mármol, obsidiana, entre otros. De este modo los objetos simbólicos estarán ligados a la religión o al poder terrestre siendo usados por las clases culturales privilegiadas: reyes, faraones, sacerdotes y nobles. 
Durante el periodo renacentista se producen una serie cambios fundamentales en la cultura y la sociedad que señalan el paso de la Edad Media a la Edad Moderna, de la vieja cultura teocéntrica medieval a un nuevo orden intelectual profano, centrado en el hombre y la naturaleza, aunque siempre en un ámbito cultural netamente cristiano.

Esta etapa se considera con el inicio de la divulgación del conocimiento tras la invención de la imprenta por Johannes Gutenberg dando lugar al Renacimiento, así como las aportaciones de los pensadores y diseñadores del siglo XV al XVIII. Esta etapa también estará delineada por nuevas invenciones mecánicas apoyadas en métodos a base de ensayo y error, los que dieron como resultado objetos como la ya mencionada imprenta, la brújula, el reloj de péndulo, el termómetro, se perfecciona la fabricación del vidrio, la construcción de barcos y la fundición de metales.

En el diseño de este periodo los principios estilísticos se sustentan en las formas arquitectónicas del periodo clásico. Los muebles se rematan con cornisas y se decoran con frisos, formas de columnas y arcos en relieve.

Es la época del surgimiento del concepto de moda, y los valores estéticos seguidos de los simbólicos caracterizan esta etapa. En contraste, los objetos cotidianos son altamente pragmáticos y de materiales perecederos o poco cotizados. Estarán destinados a labores comunes y serán usados por las clases sociales menos favorecidas.

Lo tecnológico se aplica orientado al confort, con ello mecanismos sencillos operan para facilitar las tareas, pero aún se privilegia la forma y el ornato sobre la función y el confort, ya que lo estético estará ligado al estatus.

El ornato es considerado signo de refinamiento, y prevalece sobre la idea del valor del material: el valor del objeto recae más en su ornamentación que en el material utilizado. De este modo, los objetos simbólicos están ligados con la aristocracia, la nobleza y el clero.

\section{Diseño en el siglo XIX}

En el siglo XIX, como consecuencia de la Revolución Industrial, "lo funcional prevalece sobre lo estético" (Gay y Samar, 2007: 217). La industria resuelve de manera inicial la función y el medio de producción no posibilita el detalle y el ornato. En la producción industrial, la función se impone definiendo la economía de la producción en serie. Se resuelve la necesidad, pero se diluye la estética. El producto industrial se aleja de la artesanía y del trabajo manual.

Lo ornamental se asocia a lo humano, y se valora el objeto con carácter manual y artesanal. Por un lado, se aplaude el progreso, pero las formas con las que se ornamentan los objetos refieren a una nostalgia hacia las maneras y formas de decorar del pasado.

Lo simbólico se relaciona con los historicismos, ya que se acude a las formas antiguas para enfrentar la crisis derivada del producto industrial considerado como frío e inhumano. 


\section{Diseño en el siglo $X X$}

En este periodo, acotado en los primeros 70 años del siglo $\mathrm{XX}, \mathrm{y}$ como consecuencia de la crisis derivada por las guerras mundiales, la economía exige cubrir las necesidades funcionales y renunciar al adorno, por encarecer el producto (Loos, 1998). Asimismo, esta idea es promovida por ideologías comunistas y socialistas. Se privilegia la función sobre otros principios del diseño, misma idea que se consolida con el desarrollo y teorización de ideas como ergonomía, antropometría, etc.; surgidas de escuelas de diseño como La Bauhaus o la Escuela de Ulm (Gay y Samar, 2007: 146). Con ello, el concepto estético se redefine: el ornato se elimina, y se recurre a la estilización de los componentes esenciales del objeto de diseño.

Luis Rodríguez sostiene que "el diseño moderno parte de un análisis de las necesidades y el contexto, para guiar un proceso racional, que desemboca en la especificación de aquellos factores que determinan las soluciones formales" (Rodríguez, 2010:2).

Este fenómeno racional y funcional también será ocasionado por las limitaciones tecnológicas que se tienen para el desarrollo de lo ornamental.

Lo simbólico se liga al arte, a una muestra de la creación artística del hombre. Se fomenta el concepto de arte-objeto, por lo que se considera el valor del objeto por el objeto mismo. El objeto se aprecia por su estética y su vanguardia. El diseñador se eleva al carácter de artista, al grado que suele desvincularse con necesidades reales. El objeto único o de edición limitada será altamente cotizado.

\section{Diseño en la posmodernidad}

La posmodernidad está considerada a partir de los años 70 y su principal referente será la globalización. En la posmodernidad el valor más destacado del diseño radica en lo simbólico, el cual "se liga a la tecnología, pero al mismo tiempo se ciñe a discursos como lo antrópico (emocional, cultural y psicológico), lo sustentable, lo incluyente y lo identitario como respuesta a la globalización” (Battista, 2015: 165).

La globalización es un fenómeno social, político y económico, caracterizado por multiplicidad de conexiones y estrecha interdependencia entre estados y sociedades, consecuencia directa del alto grado de tecnologización a nivel mundial y del carácter global de la red de mercados financieros. "La consecuencia es el desplazamiento progresivo de la esfera de lo local hacia el ámbito más complejo de lo global y la reedificación simbólica de las actitudes y comportamientos humanos, provocando una hibridación cultural de identidades, espacios, situaciones y procesos culturales" (Solano, 2012: 78).

Como consecuencia de este fenómeno, se desvela la necesidad de aminorar la crisis cultural en la que la sociedad se ha sumergido propugnando por la revalorización de culturas locales y por la reconsideración a un primer plano de terceras culturas. 
La multiplicidad cultural, la globalización, la concepción del universo en no-equilibrio y el desarrollo de la teoría del caos, terminan por derrumbar la concepción de que los fenómenos obedecen de manera científica y natural a estructuras dominantes prevalecientes.

Por su parte, la función se atiende bajo el concepto de multifunción, flexibilidad y libre uso del objeto. La economía se convierte en el eje rector de los procesos productivos, determinada por menor inversión, y mayor ganancia; es decir, el diseño casual y no causal, culturalmente hablando, se potencializa. El valor de lo estético y cultural radica en el pasado: como concepto nostálgico se impone lo retro, lo vintage (Solano, 2017: 3), en una gala de descontextualización. La estética simula materiales con productos sintéticos.

Como conclusión, y como se observa en la tabla 1, a lo largo de las diferentes etapas analizadas existe un comportamiento iterativo del diseño que deambula entre las tres categorías identificadas: lo funcional, lo formal/estético y lo simbólico, pero asimismo algunas etapas se han caracterizado por estar dominadas por dicotomías.

Como se aprecia en este análisis, los periodos más remotos como lo son la prehistoria y la edad antigua sucumben ante el peso de sus creencias, por lo que lo simbólico predomina. La época prehistórica se acompaña de una preocupación por la función primitiva del objeto y la edad antigua se acompaña de lo estético. Para los periodos que le continúan la dinámica cambia: en la era moderna predomina lo estético seguido de lo simbólico y en el siglo XIX la función se establece dejando en segundo lugar a lo estético. Finalmente, los últimos periodos se vuelcan sobre lo funcional (siglo XX) y se aprecia el retorno a lo simbólico en el siglo XXI, pero simultáneamente, también se desarrolla el diseño que se aleja de las condicionantes culturales y privilegia los beneficios económicos.

\section{RESULTADOS Y DISCUSIONES: ITERACIÓN CÍCLICA DEL DISEÑO Y SUS CONDICIONANTES CULTURALES}

Existe en la historia del diseño evidencia de una dinámica cíclica, donde, si bien restringidos a condicionantes de tecnología, los discursos oscilan entre la mesura y el recargo, entre lo estrictamente funcional y lo estético, para en ciertos momentos incursionar en lo simbólico. Una eterna negación de los paradigmas anteriores ha acompañado al hombre que sucumbe frente a la seductora idea de lo moderno, como concepto de superación y alejamiento del pasado.

En la figura 1, se refiere la manera en que la humanidad ha transcurrido por el diseño, y cómo sus tendencias han derivado en cierta iteración cíclica. Como se aprecia, a lo largo de la historia, el diseño ha oscilado entre las tres categorías mencionadas, siendo iterativa la carga que las condicionantes culturales han tenido. 


\section{UN DISEÑO ITERATIVO \\ se entiende como un fenómeno que responde repetida y cíclicamente a múltiples categorías, OUE VAN DESDE EL SESGO SIMBÓLICO, ESTÉTICO Y FUNCIONAL.}

Un diseño iterativo se entiende como un fenómeno que responde repetida y cíclicamente a múltiples categorías, que van desde el sesgo simbólico, estético y funcional.

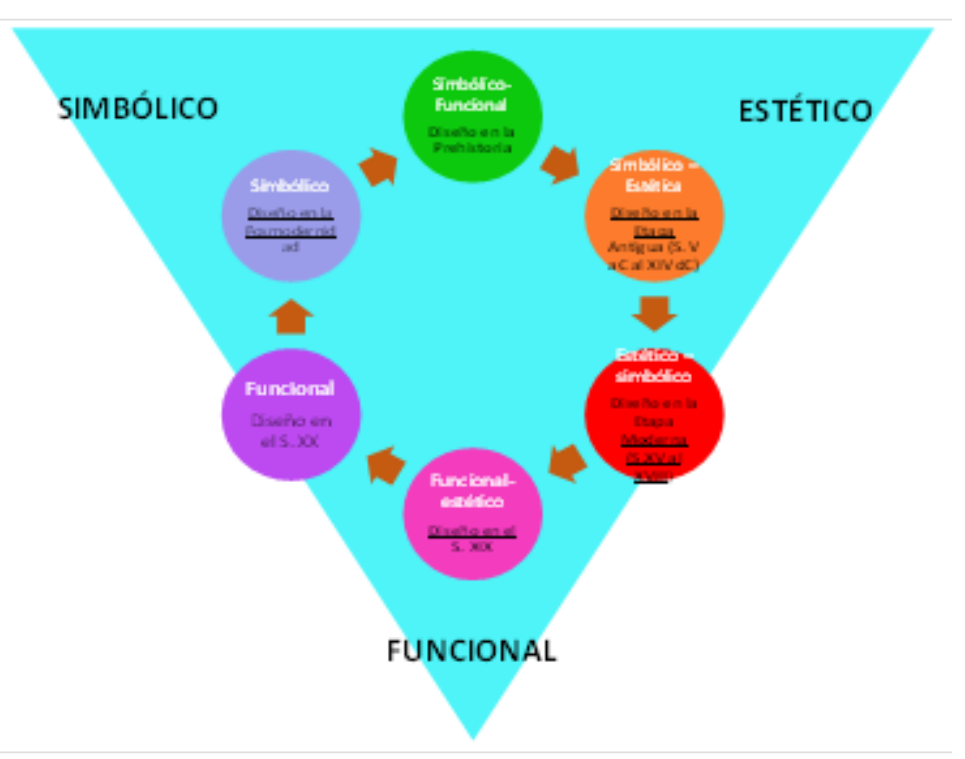

Figura 1. Esquema cíclico de la hegemonía de las categorías que imperan en el diseño a lo largo de la historia.

Fuente: Solano, 2017.

Esta repetición constante en los fenómenos humanos ha sido denominada círculo dialéctico o comportamiento pendular como analogía para comprender que la naturaleza del hombre siempre lo estará enfrentando con los paradigmas anteriores.

\section{CONCLUSIONES}

El diseño nos ha mostrado a lo largo de su historia la manera telésica en que consciente o inconscientemente ha ido respondiendo a las múltiples necesidades humanas y a sus condicionantes culturales, que evidentemente van de la mano. Pero también ha evidenciado que las hegemonías de algunas teorías pueden detonar en planteamientos que alejan el discurso de una realidad, que, aunque han contribuido a cambios por oposición, en su mayoría no permean por apartarse de una realidad cercana. Bajo este concepto, el diseño implica una propuesta en contrasentido a la inercia social, que se aleja de las necesidades reales en aras de otros intereses.

La lectura del análisis de los comportamientos de las condicionantes culturales y su respuesta de diseño, tanto en su eje longitudinal y transversal, desvela un comportamiento telésico ya descrito como cíclico, 
donde los valores del diseño se van imponiendo unos sobre otros, a razón de las demandas culturales de la época.

Resulta indiscutible la relación recíproca y de interdependencia que las condicionantes culturales y el diseño han mostrado. El diseño siempre responde a las condicionantes que le rodean, por que le son inherentes los avances tecnológicos, las demandas de la sociedad, los paradigmas estéticos, etc. El diseñador nunca podrá sustraerse de su realidad circundante, y al emerger él mismo de este contexto, su propuesta de diseño ha de dialogar con el usuario con el que comparte ese mismo contexto. Racionalizar este enfoque contextual en la formación de diseñadores, contribuirá para que la propuesta de diseño sea consciente, situada y sistematizada; y de esta manera sustente el argumento sobre el cual el diseñador conceptualiza su propuesta.

\section{FUENTES DE CONSULTA}

Battista, E. (2015), La historia del diseño industrial reconsiderada. María del Rosario Bernatene (ed.), Universidad Nacional de La Plata, La Plata.

Beuchot, M. (2008), Perfiles esenciales de la hermenéutica, Fondo de Cultura Económica, México.

García, R. (2011), Sistemas Complejos. Conceptos, método y fundamentación epistemológica de la investigación interdisciplinaria, Gedisa, Barcelona. [En línea] http://revistas.unam.mx/index.php/inter/ article/viewFile/46545/41797, consultado el 26 de mayo de 2019.

Gay, A., Samar, L. (2007), Historia de diseño industrial, Ediciones TEC, Cordoba.

Geertz, C. (2000), La interpretación de las culturas, Gedisa, México.

Giménez, G. (2001), Globalización y cultura, Colegio de México, México.

Jamenson, F. (1999), El giro cultural, Manantial, Buenos Aires.

Loos, A. (1998), Ornamente and crime, Ariadne Press, Riverside, California.

Margolín, V. (2005), Las políticas de lo artificial. Ensayos y estudios sobre diseño, Designio, México.

Mélich, J.C. (1998), Antropología simbólica y acción educativa, Paidos, Barcelona.

Morin, E. (2009), Introducción al pensamiento complejo, Gedisa, Barcelona.

Papanek (2014), Diseñar para el mundo real. Ecología humana y cambio social, Pol.len editions, Barcelona.

Rodríguez, L. (2010), El diseño en la posmodernidad: discursos y tesis. [En línea] https://www.academia.edu/229965/Dise \%C3\%B1o_y_posmodernidad_discursos_y_tesis, consultado el 15 de agosto de 2017.

Solano Meneses, E. E. (2012), Crítica Arquitectónica Sistémica: Un enfoque cognitivo, semiótico y simbólico, UAEM, México.

Solano Meneses, E. E. (2017), "Diseño Iterativo en arquitectura: ¿Crisis tipológica o práctica sustentable? Caso de estudio: El Ateneo, Buenos Aires". Memorias: DISEÑO CONCIENCIA IX Congreso Internacional de Diseño de La Habana. Editado por FORMA, consultado el 4 de septiembre de 2017. 